\title{
Development and Validation of a New Diabetes Risk Score in Guyana
}

Julia Lowe (1) - Calvin Ke $\cdot$ Kavita Singh • Reeta Gobin •

Gerald Lebovic $\cdot$ Brian Ostrow

Received: January 3, 2020 / Published online: February 18, 2020

(C) The Author(s) 2020

\section{ABSTRACT}

Introduction: We present a new diabetes risk score developed and validated in a multi-ethnic population in Guyana, South America. Measurement of in-country diabetes prevalence is a vital epidemiologic tool to combat the pandemic. It is believed that for every person

Enhanced Digital Features To view enhanced digital features for this article go to https://doi.org/10.6084/ m9.figshare. 11710083 .

Electronic Supplementary Material The online version of this article (https://doi.org/10.1007/s13300020-00775-4) contains supplementary material, which is available to authorized users.

J. Lowe $(\bowtie) \cdot$ C. Ke

Division of Endocrinology and Metabolism, Department of Medicine, University of Toronto, Toronto, Canada

e-mail: Julia.Lowe@newcastle.edu.au

K. Singh

Chronic Diseases Unit, Ministry of Public Health, Lot 1 Brickdam St., Georgetown, Guyana

R. Gobin

Master of Public Health Programme, University of Guyana, Turkeyan Campus, Georgetown, Guyana

G. Lebovic

Applied Health Research Centre, St. Michael's

Hospital, Toronto, Canada

B. Ostrow

Department of Surgery, University of Toronto,

Toronto, Canada diagnosed with type 2 diabetes there is another undiagnosed. The International Diabetes Federation (IDF) recommends a two-step detection programme using a risk score questionnaire to identify high-risk individuals followed by glycaemic measure.

Methods: Data on 798 persons from the 2016 STEPwise Approach to Chronic Disease Risk Factor Surveillance (STEPS) were used to correlate responses to 36 questions with glycated haemoglobin (HbA1C) and fasting plasma glucose (FPG) results. Bootstrapping was used to internally validate the derived seven-variable model. This model with the addition of family history questions was tested in a convenience sample of 659 Guyanese adults and externally validated in a cohort of another 528 .

Results: An 8-item Guyana Diabetes Risk Score (GDRS) was derived. The final model performed with an area under the curve (AUC) of 0.812

Conclusions: The validated eight-item Guyana Diabetes Risk Score will be extremely useful in identifying individuals at high risk of having diabetes in Caribbean, Black or East Indian populations.

Keywords: Community screening; Diabetes mellitus; Risk score; Sensitivity and specificity; Validation 


\section{Key Summary Points}

Why carry out this study?

A two-step diabetes screening programme (risk score followed by a glycaemic measure) is recommended.

Most risk scores have been developed in Caucasian populations and few have been properly internally and externally validated.

\section{What was learned from the study?}

A risk score developed from a nationally representative sample and validated in two convenience samples had an area under the curve (AUC) of 0.812 .

The eight-item Guyana Diabetes Risk Score is suitable for screening for diabetes in African and Indian Caribbean lineage populations.

\section{INTRODUCTION}

Type 2 diabetes (T2D) has a long asymptomatic pre-clinical phase which frequently goes undetected. It is generally recognized that for every person diagnosed with T2D there is another undiagnosed. The Addition-Europe trial concluded that "major benefits are likely to accrue from the early diagnosis and treatment of glycaemia and cardiovascular risk factors in type 2 diabetes" [1]. The International Diabetes Federation (IDF) recommends a two-step detection programme based on identification of high-risk individuals using a risk questionnaire followed by glycaemic measures [2]. It is estimated that three-quarters of people with diabetes live in low- and middle-income countries [3].

Guyana, the second poorest country in South America, is a small English-speaking country of 750,000 people of mostly African and East Indian descent. Risk scores developed in Caucasian populations cannot be applied to other populations of diverse ethnic origin [4]. Other risk scores developed in the region have been for Hispanic populations [5]. The Guyana Ministry of Public Health (MOPH) was interested in using a diabetes risk score in Guyana. Development of a simple Guyana Diabetes Risk Score (GDRS) became a core objective of the Guyana Diabetes Care Project. We used data from a national risk factor survey to estimate prevalence of diabetes, undiagnosed diabetes and gender ratios [6]. We then correlated answers on this survey with diabetes status and developed a model to predict risk of diabetes. In this article we present a new eight-point diabetes risk score, the GDRS, developed and validated in Guyana.

\section{METHODS}

\section{Risk Score Development: Derivation Cohort}

In 2016, the Guyana MOPH carried out a World Health Organization (WHO) STEPwise Approach to Chronic Disease Risk Factor Surveillance (STEPS). This national survey was conducted in all ten regions of Guyana in adults between ages 25 and 70 years. A multistage cluster sampling technique was used and participants selected using the Kish method [7]. Since fasting plasma glucose (FPG) and glycated haemoglobin (HbA1c) were measured in a survey segment, diabetes prevalence could be estimated and is detailed separately [6]. HbA1c was measured at the Georgetown Public Hospital Corporation using a high-performance liquid chromatography assay $\left(\mathrm{D}-10^{\circledR}\right)$. We used the WHO criteria of either FPG $\geq 126 \mathrm{mg} / \mathrm{dl}$ $(7 \mathrm{mmol} / \mathrm{l})$ or $\mathrm{HbA} 1 \mathrm{c} \geq 6.5 \%(48 \mathrm{mmol} / \mathrm{mol})$ to diagnose diabetes [2] in this cohort (see Fig. 1).

We analyzed the relationship between the biochemical diagnosis of diabetes and responses to 36 STEPS questions (see Appendix 1 in ESM). We carried out both unadjusted and multivariable logistic regression to examine the association of pre-specified literature-derived variables [8] [known diabetes; on treatment for diabetes; age; sex; family history of diabetes; ethnicity; blood pressure and body mass index (BMI)] with 


\section{Derivation cohort}

Design: Multistage cluster sample national survey from STEPS Measures: Fasting venous glucose $+\mathrm{HbA} 1 \mathrm{c}$

805 persons with records
from STEPS survey linkable
to FBG or HbA1c results ${ }^{6}$
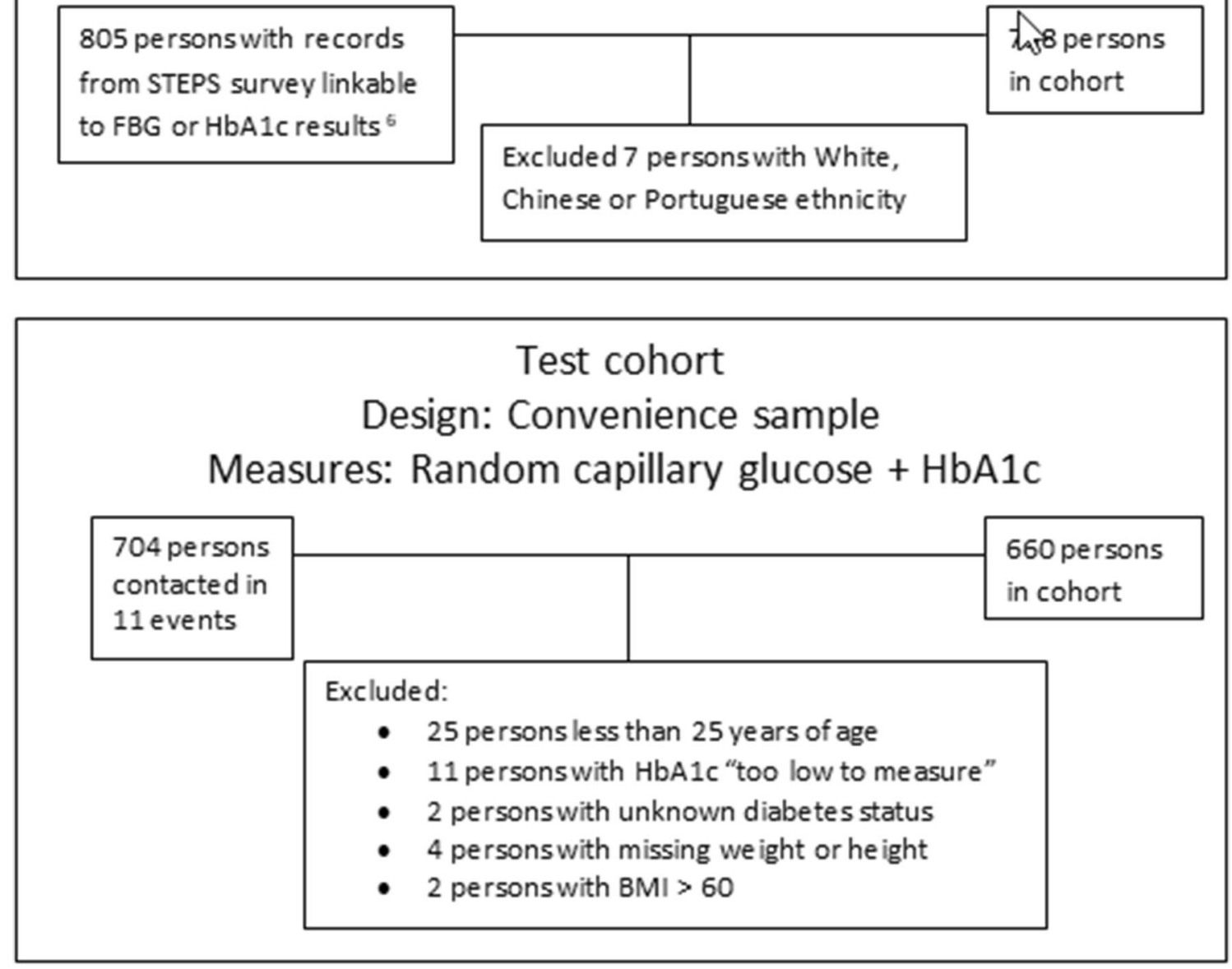

\section{Validation cohort \\ Design: Convenience sample}

Measures: Random capillary glucose $+\mathrm{HbA} 1 \mathrm{c}$

\begin{tabular}{|l|l|l|}
\hline \multirow{2}{*}{$\begin{array}{l}528 \text { persons } \\
\text { contacted in } \\
13 \text { events }\end{array}$} & \multicolumn{2}{|c|}{$\begin{array}{l}523 \text { persons } \\
\text { in cohort }\end{array}$} \\
\cline { 2 - 3 } & $\begin{array}{r}\text { Excluded: } \\
15 \text { persons with unknown diabetes status }\end{array}$ \\
\hline
\end{tabular}

Fig. 1 Flow diagram of cohorts to derive and validate the Guyana Diabetes Risk Score 
diabetes status in participants whose glycaemic measure could be linked to responses in STEPS questions. The receiver-operator characteristic (ROC) curve was plotted and the area under the curve (AUC) calculated. Bootstrapping was used to internally validate the model. Results of this analysis were used to select relevant variables for the GDRS questionnaire. Family history questions were inadvertently omitted from the STEPS survey. Since family history is known to be associated with T2D, we added family history questions to the two subsequent cohorts.

\section{Risk Score Development: Test Cohort}

The GDRS questionnaire was tested in a convenience sample of Guyanese consenting adults over 25 years of age associated with the Congregations Taking Action against NCDs (CONTACT) Study [9]. The biochemical diagnosis of diabetes was defined as $\mathrm{HbA} 1 \mathrm{c} \geq 6.5 \%$ ( $48 \mathrm{mmol} / \mathrm{mol}$ ) or random capillary blood glucose $(\mathrm{RBG}) \geq 200 \mathrm{mg} / \mathrm{dl}(11.1 \mathrm{mmol} / \mathrm{l})$ as the population was not fasting. The variables of the two cohorts were matched across both data sets. Standardized mean differences (SMD) were used to compare the derivation and test cohorts. A SMD $<0.1$ indicates the groups were similar [10]. Multivariable analysis similar to the STEPS cohort was performed. Odds ratios (OR) (95\% CI) for unadjusted and adjusted models were calculated. We examined the possibility of nonlinear relationships for several continuous variables using restricted cubic splines with three knots. We transformed the final model into a simple point system to improve ease of use [11].

\section{External Validation: Validation Cohort}

Using the statistical weights derived from the test sample, the GDRS was externally validated in a convenience sample of non-fasting persons attending $13 \mathrm{MOPH}$ health outreach events (Fig. 1). Participants were defined as having diabetes if they had a blood sugar $\geq 200 \mathrm{mg} / \mathrm{dl}$ $(11.1 \mathrm{mmol} / \mathrm{l})$ (irrespective of the last food eaten) or an $\mathrm{HbA} 1 \mathrm{c} \geq 6.5 \%(48 \mathrm{mmol} / \mathrm{mol})$.

We measured the performance of the risk score model derived from the test cohort using the validation cohort. We described model discrimination using the c-statistic and calibration using Brier's score and examined for model over-fitting.

Missing data were minimal $(<5 \%)$ and handled by complete case analysis. All analyses were performed in $\mathrm{R}$ using the RMS package [12].

\section{Ethical Approval}

All phases of this study received approval from Guyana's Institutional Review Board FWA00014641 as Protocol \#278. Persons with elevated blood tests suggesting diabetes were contacted by MOPH. The study was conducted in accordance with the Declaration of Helsinki 1964 and its later amendments. Informed consent was obtained from all participants of this study.

\section{RESULTS}

The numbers and exclusions in each cohort are shown in Fig. 1. We eliminated those variables (smoking, exercise, diet) not strongly correlated with diabetes status in the STEPS cohort. Since waist circumference and BMI are highly correlated $(\rho=0.8)$ and result in multicollinearity, $\mathrm{MOPH}$ opted to use BMI only.

There were some demographic differences between the three cohorts (Table 1). AfroGuyanese made up 39\% of the GDRS test cohort, $46.7 \%$ of the validation cohort and $29 \%$ of the STEPS cohort. Persons of Afro-Guyanese ethnicity are generally considered to constitute $30 \%$ of the population [13]. The Indo-Guyanese percentages are $39 \%, 41 \%$ and $23.1 \%$, respectively. The GDRS test cohort had only $1 \%$ persons with Amerindian ethnicity, while STEPS had $9 \%$ and the validation cohort $4.6 \%$. The mean age and SD also differ: 49.1 (14.1) for the GDRS test cohort, 47.2 (14.1) for the validation cohort and 41.8 (14.5) for the STEPS. Finally, the overall percentage with diabetes in the test cohort was higher at $28 \%$.

Odds ratios (95\% CI) for unadjusted and adjusted models for the GDRS test cohort are shown in Table 2 . There was a strong correlation 
Table 1 Comparison GDRS and STEPS cohorts

\begin{tabular}{|c|c|c|c|c|c|c|c|c|}
\hline & $\begin{array}{l}\text { GDRS } \\
\text { validation DM } \\
\text { positive }\end{array}$ & $\begin{array}{l}\text { GDRS test- } \\
\text { DM } \\
\text { positive }\end{array}$ & $\begin{array}{l}\text { STEPS- } \\
\text { DM } \\
\text { positive }\end{array}$ & SMD & $\begin{array}{l}\text { GDRS } \\
\text { validation DM } \\
\text { negative }\end{array}$ & $\begin{array}{l}\text { GDRS test- } \\
\text { DM } \\
\text { negative }\end{array}$ & $\begin{array}{l}\text { STEPS- } \\
\text { DM } \\
\text { negative }\end{array}$ & SMD \\
\hline Number & 213 & 186 & 136 & & 309 & 474 & 662 & \\
\hline $\begin{array}{l}\text { Told have } \\
\text { diabetes (\%) }\end{array}$ & $94(44.1)$ & $96(51.6)$ & $64(47.1)$ & 0.091 & $19(6.1)$ & $50(10.5)$ & $32(4.8)$ & 0.216 \\
\hline $\begin{array}{l}\text { Currently } \\
\text { treated for } \\
\text { T2D (\%) }\end{array}$ & $76(35.7)$ & $71(38.2)$ & $55(40.4)$ & 0.046 & $9(2.9)$ & $25(5.3)$ & $17(2.6)$ & 0.140 \\
\hline $\begin{array}{l}\text { Age (years) } \\
\text { (SD) }\end{array}$ & $53.43(13.27)$ & $\begin{array}{l}53.67 \\
(12.97)\end{array}$ & $\begin{array}{l}49.82 \\
\quad(12.33)\end{array}$ & 0.304 & $42.85(13.07)$ & $\begin{array}{l}46.99 \\
(13.96)\end{array}$ & $\begin{array}{l}40.17 \\
\quad(14.32)\end{array}$ & 0.482 \\
\hline $\begin{array}{c}\text { Sex }=\text { male } \\
(\%)\end{array}$ & $59(27.7)$ & $53(28.5)$ & $40(29.4)$ & 0.020 & $81(26.2)$ & $154(32.5)$ & $252(38.1)$ & 0.117 \\
\hline $\mathrm{FH}$ & & & & NA & & & & NA \\
\hline $\begin{array}{l}\text { Both parents } \\
\quad(\%)\end{array}$ & $10(4.7)$ & $8(4.3)$ & NA & & $11(3.6)$ & $15(3.2)$ & NA & \\
\hline $\begin{array}{l}\text { Both parents } \\
\text { and sibling } \\
(\%)\end{array}$ & $7(3.3)$ & $6(3.2)$ & NA & & $1(0.3)$ & $6(1.3)$ & NA & \\
\hline $\begin{array}{c}\text { Do not know/ } \\
\text { other }(\%)\end{array}$ & $8(3.8)$ & $9(4.8)$ & NA & & $22(7.1)$ & $24(5.1)$ & NA & \\
\hline None (\%) & $95(44.6)$ & $56(30.1)$ & NA & & $196(63.4)$ & $248(52.3)$ & NA & \\
\hline $\begin{array}{l}\text { One parent } \\
(\%)\end{array}$ & $59(27.7)$ & $65(34.9)$ & NA & & $56(18.1)$ & $133(28.1)$ & NA & \\
\hline $\begin{array}{l}\text { One parent } \\
\text { and sibling } \\
(\%)\end{array}$ & $7(3.3)$ & $21(11.3)$ & NA & & $0(0)$ & $19(4.0)$ & NA & \\
\hline Sibling (\%) & $27(12.7)$ & $21(11.3)$ & NA & & $23(7.4)$ & $29(6.1)$ & NA & \\
\hline Ethnicity & & & & 0.442 & & & & 0.410 \\
\hline $\begin{array}{l}\text { African/Black } \\
\quad(\%)\end{array}$ & $94(44.1)$ & $80(43.0)$ & $36(26.5)$ & & $150(48.5)$ & $181(38.2)$ & $198(29.9)$ & \\
\hline $\begin{array}{l}\text { Amerindian } \\
(\%)\end{array}$ & $6(2.8)$ & $3(1.6)$ & $11(8.1)$ & & $18(5.8)$ & $5(1.1)$ & $64(9.7)$ & \\
\hline $\begin{array}{l}\text { East Indian } \\
(\%)\end{array}$ & $66(31.0)$ & $75(40.3)$ & $68(50.0)$ & & $54(17.5)$ & $181(38.2)$ & $264(39.9)$ & \\
\hline $\begin{array}{l}\text { Mixed/other } \\
\text { (\%) }\end{array}$ & $47(22.1)$ & $28(15.1)$ & $21(15.4)$ & & $87(28.2)$ & $107(22.6)$ & $136(20.5)$ & \\
\hline
\end{tabular}


Table 1 continued

\begin{tabular}{|c|c|c|c|c|c|c|c|c|}
\hline & $\begin{array}{l}\text { GDRS } \\
\text { validation DM } \\
\text { positive }\end{array}$ & $\begin{array}{l}\text { GDRS test- } \\
\text { DM } \\
\text { positive }\end{array}$ & $\begin{array}{l}\text { STEPS- } \\
\text { DM } \\
\text { positive }\end{array}$ & SMD & $\begin{array}{l}\text { GDRS } \\
\text { validation DM } \\
\text { negative }\end{array}$ & $\begin{array}{l}\text { GDRS test- } \\
\text { DM } \\
\text { negative }\end{array}$ & $\begin{array}{l}\text { STEPS- } \\
\text { DM } \\
\text { negative }\end{array}$ & SMD \\
\hline $\begin{array}{l}\text { Mean } \\
\text { SBP(SD) }\end{array}$ & $136.48(21.27)$ & $\begin{array}{l}139.16 \\
(22.27)\end{array}$ & $\begin{array}{l}140.69 \\
(39.31)\end{array}$ & 0.048 & $124.37(18.03)$ & $\begin{array}{l}130.78 \\
(21.74)\end{array}$ & $\begin{array}{l}126.68 \\
(21.72)\end{array}$ & 0.188 \\
\hline $\begin{array}{l}\text { Mean } \\
\text { DBP(SD) }\end{array}$ & 75.27 (16.72) & $\begin{array}{l}84.46 \\
\quad(13.19)\end{array}$ & $\begin{array}{l}86.40 \\
\quad(13.60)\end{array}$ & 0.145 & $72.40(14.78)$ & $\begin{array}{l}79.34 \\
\quad(14.43)\end{array}$ & $\begin{array}{l}78.73 \\
\quad(13.02)\end{array}$ & 0.045 \\
\hline $\begin{array}{l}\text { BMI [mean] } \\
\quad(\mathrm{SD})\end{array}$ & $31.10(17.40)$ & $30.34(5.73)$ & $\begin{array}{l}29.48 \\
\quad(6.08)\end{array}$ & 0.146 & $30.17(23.82)$ & $28.80(6.34)$ & $\begin{array}{l}26.91 \\
\quad(6.46)\end{array}$ & 0.296 \\
\hline
\end{tabular}

Told diabetes. Answered yes to question "Have you ever been told you have diabetes or high blood sugar?" GDRS Guyana Diabetes Risk Score, T2D Type 2 Diabetes, $F H$ family history, SBP systolic blood pressure, DBP diastolic blood pressure, STEPS STEPwise Approach to Chronic Disease Surveillance

between previous diagnosis of diabetes or current treatment and diabetes diagnosis. Age, mean diastolic blood pressure (DBP) and BMI were also strongly correlated with diabetes. Using the STEPS data alone, the ROC curve had an AUC of 0.829 for the entire sample and 0.734 for those not known to have elevated blood sugar. The internal bootstrap validation indicated minor overfitting. The slope shrinkage factor was 0.930 and the Somers' Dxy had a

Table 2 GDRS test survey: unadjusted and adjusted models

\begin{tabular}{|c|c|c|c|c|c|c|c|}
\hline \multirow[t]{2}{*}{ Parameter } & \multicolumn{4}{|c|}{ Unadjusted model } & \multicolumn{3}{|c|}{ Adjusted model } \\
\hline & $\overline{\mathrm{OR}}$ & Lower 0.95 & Upper 0.95 & $\overline{\text { Cstat }}$ & $\overline{\mathrm{OR}}$ & Lower 0.95 & Upper 0.95 \\
\hline Told diabetes yes: no & 9.045 & 5.999 & 13.638 & 0.705 & 3.764 & 2.013 & 7.040 \\
\hline Treatment for diabetes & 11.088 & 6.727 & 18.277 & 0.664 & 2.815 & 1.318 & 6.013 \\
\hline Age & 1.416 & 1.248 & 1.608 & 0.644 & 1.137 & 0.969 & 1.335 \\
\hline Sex-M:F & 0.828 & 0.571 & 1.201 & 0.520 & 0.936 & 0.599 & 1.461 \\
\hline $\mathrm{FH}$ at least 1 parent vs. none & 2.560 & 1.750 & 3.745 & 0.621 & 1.888 & 0.787 & 4.530 \\
\hline FH only sibling vs. none & 3.207 & 1.704 & 6.034 & - & 1.850 & 1.186 & 2.887 \\
\hline Do not know/other vs. none & 1.661 & 0.732 & 3.767 & - & 1.984 & 0.922 & 4.272 \\
\hline Ethnicity Amerindian: African/Black & 0.737 & 0.172 & 3.157 & 0.544 & 1.505 & 0.274 & 8.279 \\
\hline Ethnicity East Indian: African/Black & 0.691 & 0.161 & 2.963 & - & 0.647 & 0.404 & 1.038 \\
\hline Ethnicity mixed/other: African/Black & 0.436 & 0.098 & 1.936 & - & 0.636 & 0.363 & 1.116 \\
\hline Mean SBP/10 point. change & 1.180 & 1.093 & 1.273 & 0.621 & NA & NA & NA \\
\hline Mean DBP/10 point. change & 1.281 & 1.136 & 1.444 & 0.620 & 1.202 & 1.038 & 1.391 \\
\hline BMI per 1 unit & 1.040 & 1.012 & 1.068 & 0.588 & 1.037 & 1.003 & 1.072 \\
\hline
\end{tabular}

Told diabetes. Answered yes to question "Have you ever been told you have diabetes?"

GDRS Guyana Diabetes Risk Score, $M$ male, $F$ female, $F H$ family history, BMI body mass index, SBP systolic blood pressure, $D B P$ diastolic blood pressure 
Table 3 GDRS scoring and prediction from test cohort

\begin{tabular}{|c|c|c|c|c|c|c|c|}
\hline Risk Score & Points & Risk Score & Points & Risk Score & Points & Risk Score & Points \\
\hline \multicolumn{2}{|c|}{ Known Diabetes } & \multicolumn{2}{|l|}{ Sex } & $57-67$ & 2 & $38.6-43.7$ & 5 \\
\hline No & 0 & Female & 0 & $68-78$ & 3 & $43.8-49.0$ & 6 \\
\hline Yes & 7 & Male & 0 & $79-89$ & 4 & $49.1-54.2$ & 7 \\
\hline \multicolumn{2}{|c|}{ Diabetes treatment } & \multicolumn{2}{|l|}{ Family History } & $90-100$ & 5 & $54.3-59.5$ & 8 \\
\hline No & 0 & Any parent plus & 3 & $101-111$ & 6 & $>59.5$ & 9 \\
\hline Yes & 5 & Only sibling & 4 & $112-122$ & 7 & Total Points & $\begin{array}{l}\text { Probability of } \\
\text { Diabetes }\end{array}$ \\
\hline \multicolumn{2}{|l|}{ Age } & $\begin{array}{l}\text { One Parent/ Don't } \\
\text { Know/ Other }\end{array}$ & 3 & $123-133$ & 8 & $8-11$ & $0.1-.166$ \\
\hline $25-31$ & 0 & None & 0 & $134-144$ & 9 & $12-14$ & $0.195-.264$ \\
\hline $32-46$ & 1 & \multicolumn{2}{|l|}{ Ethnicity } & $\geq 145$ & 10 & $15-16$ & $0.304-.347$ \\
\hline $47-60$ & 2 & Black/African & 2 & \multicolumn{2}{|c|}{ Body Mass Index } & $17-19$ & $0.392-.488$ \\
\hline $61-74$ & 3 & Amerindian & 4 & $15-17.5$ & 0 & $20-22$ & $0.537-.631$ \\
\hline $75-89$ & 4 & $\begin{array}{l}\text { East Indian/ } \\
\text { Mixed/other }\end{array}$ & 0 & $17.6-22.8$ & 1 & $23-25$ & $0.675-.755$ \\
\hline \multirow[t]{3}{*}{$\geq 90$} & 5 & \multicolumn{2}{|c|}{ Mean Diastolic Blood Pressure } & $22.9-28.0$ & 2 & $26-29$ & $0.789-.870$ \\
\hline & & $40-45$ & 0 & $28.1-33.2$ & 3 & $\geq 30$ & $\geq 0.891$ \\
\hline & & $46-56$ & 1 & $33.3-38.5$ & 4 & & \\
\hline
\end{tabular}

Table 4 Sensitivity and specificity of GDRS

\begin{tabular}{lllllll}
\hline Risk score points & No. with score & Sensitivity \% & Specificity \% & PPV \% & NPV \% & Accuracy \% \\
\hline$>5$ & 635 & 99.5 & 5.1 & 29.1 & 96.0 & 31.7 \\
$>10$ & 431 & 88.2 & 43.7 & 38.1 & 90.4 & 56.2 \\
$>15$ & 179 & 59.1 & 85.4 & 61.5 & 84.2 & 78.0 \\
$>20$ & 114 & 43.5 & 93.0 & 71.1 & 80.8 & 79.1 \\
$>25$ & 37 & 14.5 & 97.9 & 73.0 & 74.5 & 74.4 \\
$>30$ & 1 & 0.5 & 100.0 & 100.0 & 71.9 & 72.0 \\
\hline
\end{tabular}

corrected value of 0.631 with some slight overfitting as indicated from an optimism of 0.027 . The internal bootstrap validation indicated minor overfitting. The slope shrinkage factor was 0.905 and the Somers' Dxy had a corrected value of 0.540 with some slight overfitting as indicated from an optimism of 0.043 .

In the final validation cohort the c-statistic was 0.82 , close to the original c-statistic from the training model. The Brier's score was 0.136, which is fairly close to 0 , indicating good calibration. Using a likelihood ratio test we found that there was no statistically significant improvement using RCS and the linear fit was adequate. Lastly, the slope value was 0.892, indicating some minor overfitting.

The final questionnaire scoring is shown in Table 3 and the sensitivity and specificity with different scores in Table 4 . The risk score (Fig. 2) has eight variables: gender, age, known diabetes, current treatment, ethnicity, family history, diastolic BP and BMI scored based on the degree of association with diabetes. The impact of the addition of family history questions was statistically significant and improved the risk score in those with unknown diabetes status (see Appendix Table 2). We recommend that a risk score $\geq 10$, which maximizes sensitivity 


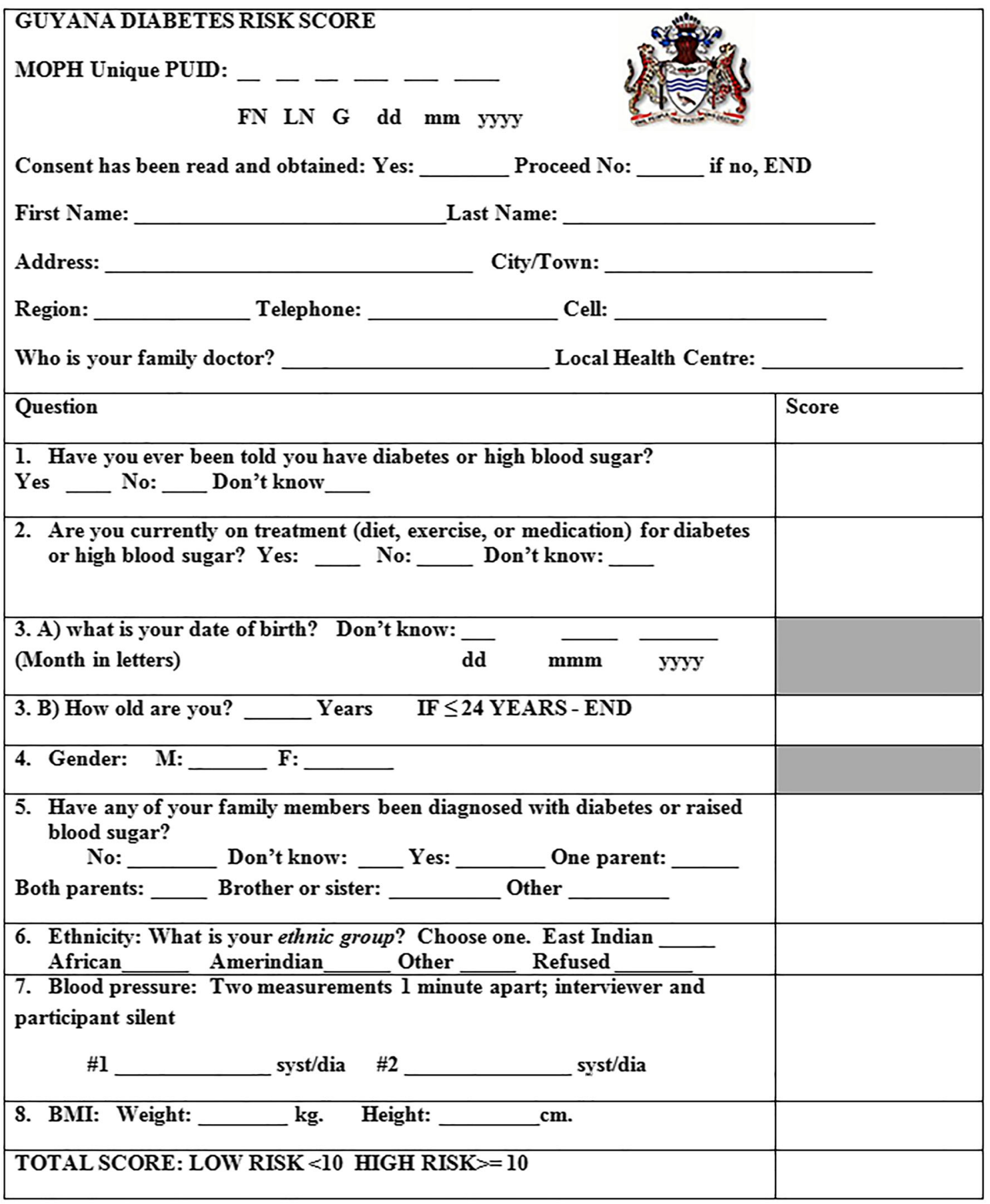

Fig. 2 Guyana Diabetes Risk Score questionnaire

with a reasonable number of false positives, be the trigger for biochemical verification of diabetes status in any subsequent surveys. Fortythree per cent of the population will be ruled "out" at this score.

\section{DISCUSSION}

Many risk scores have been developed in various countries and their methodology and reporting levels subjected to systematic review 
$[5,8]$. Use of capillary RBG as a diagnostic measure of diabetes is thought to be appropriate for population surveys [14]. Our score uses eight standard, non-invasive and easily measured variables associated with diabetes and included in many other scores: age, gender, family history of diabetes, blood pressure, BMI, ethnicity and whether participants are known to have diabetes or on treatment. Our multivariable model was developed using both statistical and clinical significance and demonstrated that the model works by bootstrapping in the STEPS derivation cohort. Because prediction models tend to perform better on the sample on which they are derived than on new data, we then externally validated the model using two completely different real-life cohorts of individuals from multiple different locations than those used to derive the model. This compensated for any optimism in the internally validated model and allowed us to add family history questions and use measures of RBG, which is better for community screening when people are unlikely to be fasting. Statistical analysis suggests the results are quite generalizable. Another strength of our study is its use of HbA1c as well as direct measures of glycaemia as it has been shown these measures identify different populations of people with dysglycaemia [15].

Some of the weights assigned to the questions seem counter-intuitive but this is a consequence of the relatively small non-random samples used to test and validate the score. There was no upper age limit in the GDRS test and validation cohorts and this may account for the mean age differences. Ethnicity differences between the three cohorts may have occurred because the STEPS questionnaire offered a mixed ethnicity option. The self-selection of persons at higher risk of diabetes in the GDRS cohorts explains the higher rate of diabetes in these cohorts.

We have had a small trial use of the score where we saw 79 people at a Health Expo over 4 days, 40 of whom were deemed high risk and referred for further management.

Our study is limited by differences in the definition of diabetes in the two surveys with FPG used in STEPS and RBG in the GDRS test and validation cohorts as well as the omission of family history in the STEPS survey. Another limitation is the inclusion of only a small number of people of Amerindian descent. Ethnic differences in risk factors for diabetes have been shown in neighbouring Suriname [16] with an absence of an association with BMI in Amerindians. Other studies have shown a lower rate of diabetes in Amerindians in remote villages [17] but higher rates associated with increased biological risk factors in urban settings [18].

\section{CONCLUSION}

Further work is needed to confirm the applicability of the GDRS to Amerindians. The total number surveyed, high diabetes rate, consistency of the results and internal and external validation suggest that the Guyana Diabetes Risk Score will be extremely useful for identifying those at high-risk of having diabetes in the Caribbean as well as countries such as the UK and Mauritius with individuals of African, East Indian or mixed descent.

\section{ACKNOWLEDGEMENTS}

We thank the Ministry of Public Health and the CONTACT study for their cooperation and all participants and staff of the Guyana Diabetes Care Project for their hard work participating in the outreaches and accumulating this information. We thank all the people in Guyana who contributed to this study either collecting or giving data for the study.

Funding. This study was supported by the World Diabetes Foundation (14-862) and a Banting and Best Sunlife Financial Impact Challenge Grant (499334) from the University of Toronto. No Rapid Service Fee was received by the journal for the publication of this article.

Authorship. All named authors meet the International Committee of Medical Journal Editors (ICMJE) criteria for authorship for this article, take responsibility for the integrity of 
the work as a whole, and have given their approval for this version to be published.

Disclosures. Julia Lowe's current affiliation is University of Newcastle, NSW, but she retains an adjunct appointment at the University of Toronto. Calvin Ke, Kavita Singh, Reeta Gobin, Gerald Lebovic and Brian Ostrow have nothing to disclose.

Compliance with Ethics Guidelines. All phases of this study received approval from Guyana's Institutional Review Board FWA00014641 as Protocol \#278. Persons with elevated blood tests suggesting diabetes were contacted by MOPH. The study was conducted in accordance with the Declaration of Helsinki 1964 and its later amendments. Informed consent was obtained from all participants of this study.

Data Availability. The data sets generated during this study are not publicly available as they are the property of the Ministry of Public Health Guyana. They may be available from the corresponding author on reasonable request if permission is granted by the Ministry of Public Health Guyana.

Open Access. This article is licensed under a Creative Commons Attribution-NonCommercial 4.0 International License, which permits any non-commercial use, sharing, adaptation, distribution and reproduction in any medium or format, as long as you give appropriate credit to the original author(s) and the source, provide a link to the Creative Commons licence, and indicate if changes were made. The images or other third party material in this article are included in the article's Creative Commons licence, unless indicated otherwise in a credit line to the material. If material is not included in the article's Creative Commons licence and your intended use is not permitted by statutory regulation or exceeds the permitted use, you will need to obtain permission directly from the copyright holder. To view a copy of this licence, visit http://creativecommons.org/licenses/bync/4.0/.

\section{REFERENCES}

1. Herman WH, Ye W, Griffin SJ, Simmons RK, Davies MJ, Khunti K, Rutten GE, Sandbaek A, Lauritzen T, Borch-Johnsen K, Brown MB, Wareham NJ. Early detection and treatment of type 2 diabetes reduce cardiovascular morbidity and mortality: a simulation of the results of the Anglo-Danish-Dutch Study of Intensive Treatment in People with ScreenDetected Diabetes in Primary Care (ADDITIONEurope). Diabetes Care. 2015;38(8):1449-555.

2. Global Guideline for Type 2 Diabetes, International Diabetes Federation, Brussels, 2012.

3. IDF Atlas. 8th Edn. 2015. https://www. diabetesatlas.org/key-messages.html

4. Glumer C, Vistisen D, Borch-Johnsen K, Colagiuri S, DETECT-2 Collaboration. Risk scores for type 2 diabetes can be applied in some populations but not all. Diabetes Care. 2006;29(2):410-4.

5. Carrillo-Larco RM, Aparcana-Granda DJ, Mejia JR, Barengo NC, Bernabe-Ortiz A. Risk scores for type 2 diabetes mellitus in Latin America: a systematic review of population-based studies. Diabet Med 2019;36:1573-84.

6. Ke C, Persaud S, Singh K, Ostrow B, Lebovic G, Hincapié C, Lowe J. Prevalence of diabetes and prediabetes in Guyana: a Nationally Representative Study. 14th Jan 2020 Submitted to Diabetes Care

7. Implementation plan STEPwise Approach to Chronic Disease risk factor surveillance (STEPS), Ministry of Public Health, Guyana, 2015.

8. Collins GS, et al. Developing risk prediction models for type 2 diabetes: a systematic review of methodology and reporting. BMC Med. 2011;9:103.

9. Caribbean Public Health Association. New trial to target preventable deaths in the Caribbean [Internet]. Jamaica. https://carpha.org/articles/ID/135/ New-trial-to-target-preventable-deaths-in-theCaribbean. Accessed 17 Feb 2017.

10. Austin PC. Using the standardized difference to compare the prevalence of a binary variable between two groups in observational research. Commun Stat Simulat Comput. 2009;38(6): 1228-344.

11. Sullivan, Lisa M, Massaro JM, D'Agostino RB Sr. Presentation of multivariate data for clinical use: the Framingham Study risk score functions. Stat Med. 2004;23(10):1631-1660. 
12. Harrell FE Jr (2018). RMS: regression modeling strategies. R package version 5.1-2. https://CRAN.Rproject.org/package=rms.

13. "2012 Census Compendium 2". Statisticsguyana.gov.gy. Accessed 24 Sept 2019.

14. Tirimacco R, et al. Should capillary blood glucose measurements be used in population surveys? IJDM. 2010;2(1):24-7.

15. NCD Risk Factor Collaboration (NCD-RisC). Effects of diabetes definition on global surveillance of diabetes prevalence and diagnosis: a pooled analysis of 96 population-based studies with 331,288 participants. Lancet Diabetes Endocrinol. 2015, 3(8): 624-37.
16. Krishnadath ISK, Nahar-van Venrooij LM, Jaddoe $\mathrm{VWV}$, et al. Ethnic differences in prediabetes and diabetes in the Suriname Health Study. BMJ Open Diabetes Res Care. 2016;4:e000186. https://doi.org/ 10.1136/bmjdrc-2015-000186.

17. Jindal RM, Soni R, Mehta K. TG patel incidence of diabetes and hypertension in indigenous Amerindian village in Guyana. S Am Indian J Nephrol. 2016;26:389-90.

18. Schulz LO, Bennett PH, Ravussin E, et al. Effects of traditional and western environments on prevalence of type 2 diabetes in Pima Indians in Mexico and the US. Diabetes Care. 2006;29:1866-71. https://doi.org/10.2337/dc06-0138. 